\title{
The influence of semantic category membership on syntactic decisions: A study using event-related potentials
}

\author{
Citation for published version (APA):
}

Schiller, N. O., Schuhmann, T., Neyndorff, A. C., \& Schmitt, B. M. (2006). The influence of semantic category membership on syntactic decisions: A study using event-related potentials. Brain Research, 1082, 153-164. https://doi.org/10.1016/j.brainres.2006.01.087

Document status and date:

Published: 01/01/2006

DOI:

10.1016/j.brainres.2006.01.087

Document Version:

Publisher's PDF, also known as Version of record

\section{Document license:}

Taverne

Please check the document version of this publication:

- A submitted manuscript is the version of the article upon submission and before peer-review. There can be important differences between the submitted version and the official published version of record.

People interested in the research are advised to contact the author for the final version of the publication, or visit the DOI to the publisher's website.

- The final author version and the galley proof are versions of the publication after peer review.

- The final published version features the final layout of the paper including the volume, issue and page numbers.

Link to publication

\footnotetext{
General rights rights.

- You may freely distribute the URL identifying the publication in the public portal. please follow below link for the End User Agreement:

www.umlib.nl/taverne-license

Take down policy

If you believe that this document breaches copyright please contact us at:

repository@maastrichtuniversity.nl

providing details and we will investigate your claim.
}

Copyright and moral rights for the publications made accessible in the public portal are retained by the authors and/or other copyright owners and it is a condition of accessing publications that users recognise and abide by the legal requirements associated with these

- Users may download and print one copy of any publication from the public portal for the purpose of private study or research.

- You may not further distribute the material or use it for any profit-making activity or commercial gain

If the publication is distributed under the terms of Article $25 \mathrm{fa}$ of the Dutch Copyright Act, indicated by the "Taverne" license above, 


\title{
Research Report
}

\section{The influence of semantic category membership on syntactic decisions: A study using event-related brain potentials}

\author{
Niels O. Schiller ${ }^{a, b, c, *}$, Teresa Schuhmann ${ }^{a}$, Alessia C. Neyndorff ${ }^{a}$, Bernadette M. Jansma $^{a}$ \\ ${ }^{a}$ Maastricht University, Faculty of Psychology, Department of Cognitive Neuroscience, P.O. Box 616, 6200 MD Maastricht, The Netherlands \\ ${ }^{\mathrm{b}}$ Max Planck Institute for Psycholinguistics, Nijmegen, The Netherlands \\ ${ }^{\mathrm{C}}$ Leiden Institute for Brain and Cognition
}

\section{A R T I C L E I N F O}

Article history:

Accepted 25 January 2006

Available online 28 February 2006

\section{Keywords:}

Psycholinguistic

Language comprehension

Semantic gender marking

Syntactic decision-making

ERP

N200

\begin{abstract}
A B S T R A C T
An event-related brain potentials (ERP) experiment was carried out to investigate the influence of semantic category membership on syntactic decision-making. Native speakers of German viewed a series of words that were semantically marked or unmarked for gender and made go/no-go decisions about the grammatical gender of those words. The electrophysiological results indicated that participants could make a gender decision earlier when words were semantically gender-marked than when they were semantically gender-unmarked. Our data provide evidence for the influence of semantic category membership on the decision of the syntactic gender of a visually presented German noun. More specifically, our results support models of language comprehension in which semantic information processing of words is initiated prior to syntactic information processing is finalized.
\end{abstract}

(c) 2006 Elsevier B.V. All rights reserved.

\section{Introduction}

Language comprehension comprises the initial processing of visual or auditory information, lexical activation and competition between candidate words, and word recognition. At some point, semantic and syntactic information needs to be retrieved from the lexicon to interpret a sequence of words syntactically and semantically. Utterance interpretation is followed by discourse integration (see reviews in Cutler and Clifton, 1999; McQueen et al., 2003).

The time course of spoken and written language comprehension has interested researchers for quite some time (see reviews in Coltheart et al., 2001; Norris et al., 2000; Seidenberg, 1995; Tanenhaus and Trueswell, 1995) because it can help to constrain theoretical models of language processing. An estimation of a time course includes the determination of a temporal order of certain processes and an estimation of the duration of those processes. Recently, several event-related potential (ERP) studies have been performed to assess the time course of information processing during language comprehension (and language production; e.g., Rodriguez-Fornells et al., 2002; Schiller et al., 2003a,b; Schmitt et al., 2000; Schmitt et al., 2001a,b; Van Turennout et al., 1997, 1998).

In language production, it has been suggested that information is processed in a strictly serial way, from conceptualsemantic nodes via lexical-syntactic nodes to word form representations (see Levelt et al., 1999 for an overview; but see Caramazza, 1997 or Dell, 1986 for a different view). According to Levelt et al. (1999), the connections between conceptual-semantic nodes and lexical nodes are bidirectional, thus allowing for feedback from lexical nodes to conceptualsemantic representations. As argued by Friederici and Jacob-

\footnotetext{
* Corresponding author. Maastricht University, Faculty of Psychology, Department of Cognitive Neuroscience, P.O. Box 616, 6200 MD Maastricht, The Netherlands. Fax: +31433884125.

E-mail address: n.schiller@psychology.unimaas.nl (N.O. Schiller).
} 
sen (1999), for language comprehension such a proposal has not been made. However, language comprehension starts with the processing of a stimulus (e.g., a visual or auditory word form) before its meaning can be extracted. At what moment in time syntactic features, such as grammatical gender, are being accessed during this process is still an open issue. In principle, there are several possibilities concerning the relative time course of activation of semantic and syntactic information. Levelt et al. (1999) suggested that from the lexical-syntactic level upwards "the perceptual and production networks coincide" (p. 7). Therefore, one might assume that syntactic information processing should precede semantic processing in comprehension. Alternatively, semantic processing may be initiated prior to syntactic processing. Moreover, if processing proceeds in parallel, semantic and syntactic information processing should occur more or less simultaneously.

To investigate the time course of language comprehension, Rodriguez-Fornells et al. (2002) examined the time course of phonological and semantic processing during language comprehension using ERPs and found that phonological analysis preceded semantic and syntactic analysis. In their study, participants heard words and were required to make dual choice go/no-go decisions depending on a word's semantic and phonological features. More specifically, participants were required to decide whether the word denoted an animal or an object (semantic feature) and whether the word started with a vowel or a consonant (phonological feature). The authors found the N200 effect generated by phonological processing to occur $85 \mathrm{~ms}$ prior to the N200 effect generated by semantic processing. The N200 is an ERP component with a peak latency that has been related to information availability (see below for details). Schmitt et al. (2001a) found additional evidence for cascaded processing. In their ERP study, the N200 was used to study the sequence of semantic and syntactic encoding. Their data demonstrated that semantic information access precedes syntactic information access in speech comprehension.

Another important aspect of language comprehension besides temporal order - is the interaction between the different processes. In a recent study, Schiller et al. (2003b) illustrated that semantic and phonological information can influence syntactic decisions in German. In their study, ERPs were measured while participants processed written German words, which were semantically and/or phonologically marked or unmarked for gender. Their data showed that participants were faster in making a decision about the appropriate gendermarked determiner when words were semantically and/or phonologically gender-marked than when this was not the case. The effect of semantic but not phonological gender marking was also reflected in earlier N200 peak latencies. Furthermore, the ERP signatures of semantic and phonological gender marking revealed an interaction. Therefore, it seems reasonable to further investigate the influence of processing stages on each other. The current study will focus on the influence of semantic properties on syntactic decisions.

One possibility to assess the influence of semantics on syntactic decision-making is investigating semantic gender assignment regularities in the German language (Zubin and Köpcke, 1986). Schwichtenberg and Schiller (2004) provided empirical evidence for the existence of semantic gender assignment regularities. They presented native German parti- cipants with two pseudowords combined with either a masculine (der) or a feminine (die) definite determiner and a semantic category. Participants were asked to decide which determiner-pseudoword combination was more likely to belong to the semantic category in question. Prior to the actual experiment, the authors selected specific semantic categories that were preferentially assigned to one specific grammatical gender. Thus, participants were, for example, presented with the semantic category Musikinstrument (musical instrument) followed by a pair of pseudowords with different determiners (der Quachtel; the masculine $_{\text {Quachtel and die Ruppel; the }}$ feminine Ruppel) and thus different gender marking. Thereafter, they were asked to decide which pseudoword was more suitable for the category. Overall, determiner-pseudoword phrases with pseudowords whose determiner was congruent with the gender-assignment of the category were selected as possible members of gender-associated categories more often and faster than determiner-pseudoword phrases with incongruent determiners. In the gender-nonassociated categories, i.e., in those semantic categories that were not found to be associated with a specific grammatical gender, Schwichtenberg and Schiller (2004) observed that masculine and feminine pseudowords were chosen equally often, supporting the idea that semantic regularities might be a part of the gender-assignment system. In sum, these results indicated that the syntactic gender-assignment system contains semantic assignment regularities.

In the present study, we specifically investigate in an online processing task whether or not semantic category membership influences syntactic decisions, using the N200. More generally, we were interested in whether or not the semantic category membership of words influences syntactic information processing in German language comprehension.

\subsection{The $\mathrm{N} 200$}

For the assessment of the temporal scheme of language processes, the use of a go/no-go paradigm can be very effective. In this paradigm, individuals are asked to respond to one class of stimuli (go trials) and to withhold their response to another class of stimuli (no-go trials). A specific ERP component was found to be related to this response inhibition, namely the N200, a fronto-central negativity approximately between 100 and $300 \mathrm{~ms}$ after stimulus onset (Gemba and Sasaki, 1989; Pfefferbaum et al., 1985; Thorpe et al., 1996). In languagerelated tasks, however, the N200 is observed much later, i.e., between 300 and 700 ms (see, e.g., Müller and Hagoort, 2006; Schiller et al., 2003a,b; Schmitt et al., 2000, 2001a,b). This N200 was more negative in no-go trials compared to go trials. The functional significance of this component is not yet clear, however, the amplitude of the N200 is seen as a function of neuronal activity required for "response inhibition" (Jodo and Kayama, 1992) occurring in a go/no-go task. Moreover, once defining the information on which the go/no-go paradigm is based, the peak latency of the N200 effect can be used to determine the moment in time at which this information is encoded, or available in such a way that a response decision can be made. Thus, "an early N200 means that the information that blocked the response on no-go trials was available early and vice versa" (Kutas and Schmitt, 2003). This was shown, for 
example, by Thorpe et al. (1996) who employed the N200 no-go effect to a visual categorization task with the aim of determining the minimum time needed for conceptual processing of pictures.

\subsection{The experimental paradigm}

The experiment was carried out in German. Native German participants saw monomorphemic nouns, one at a time, on a computer screen and were asked to classify each word according to its grammatical gender (masculine or feminine) (see Radeau and Van Berkum, 1996 for an overview of the methodology). More precisely, their task was to indicate the gender-marked definite determiner of the target word: der for masculine and die for feminine targets. Monomorphemic words of feminine and masculine gender are approximately equally distributed in the German lexicon (see Schiller and Caramazza, 2003). Participants were required to carry out a right-hand button-press if the gender was masculine ( $g \circ=$ masculine, no$g o=$ feminine) or -in anotherblock-feminine ( $g \circ=$ feminine, $n o-$ go = masculine). Grammatical gender is a lexical property of words, which is arbitrary for the most part (Corbett, 1991; Marx, 1999). However, the grammatical gender of German words can be marked by semantic category membership, i.e., certain semantic categories are biased towards a certain grammatical gender (Zubin and Köpcke, 1986).

The target words were selected out of six different categories that were found to be gender-associated categories, as suggested by Schwichtenberg and Schiller (2004). The three categories marked for feminine gender were

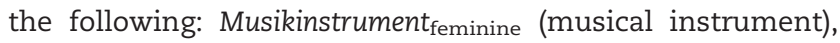
Obst $_{\text {feminine (fruit), and Insekt }}$ feminine (insect). In Schwichtenberg and Schiller's (2004) study, 72\% of the named words belonging to those categories were feminine whereas only $16 \%$ were masculine (the remaining words were neuter). The masculine marked categories included Gesteinmasculine (stone), Raubtier masculine (predator), and Gewürz masculine (spice). In the masculine categories, $68 \%$ of the named words were masculine while $22 \%$ were feminine (the remaining words were again neuter). The control categories were categories that were not found to be gender-associated with a particular gender: Körperteil (bodypart), Werkzeug (tool), Küchenutensil (kitchen utensil), Möbel (furniture), Waffen (weapon), and Kleidung (clothes). These categories thus do not exhibit an imbalance between the genders (for details see Schwichtenberg and Schiller, 2004) and therefore they do not contain any semantic information that might enhance syntactic processing. Hence, these gender-nonassociated control categories serve as a comparison to the gender-associated categories.

The present ERP study aims to use the peak latencies and amplitudes of the N200 to determine whether or not semantic information influences syntactic processing during language comprehension. If the decision about the grammatical gender was based only on syntactic information, semantic factors should not have any influence on the syntactic decision, and on the peak latency of the N200. This would be the case, for instance, if syntactic information would become available before semantic processing. On the other hand, if the syntactic decision can be influenced by semantic factors, we can use the
N200 and its shift in peak latency to estimate the time course of this semantic influence. The difference between the go and nogo responses in the N200 provides an upper limit about the point in time when the necessary information must be available in order to determine whether or not to respond. If semantic information about gender accelerates the syntactic decision, then the N200 should arise earlier for words with semantic gender marking, compared to words without semantic gender marking. This would imply that semantic processing of words is at least initiated before syntactic processing is completed.

\section{Results}

\subsection{Button-press latencies}

Reaction times (RTs) faster than 300 ms or slower than $1,500 \mathrm{~ms}$ were excluded from the analysis. Less than $1 \%$ of the correct responses fell outside these trimming criteria. Semantically gender-unmarked targets (660 ms) were responded to faster than semantically gender-marked ones (690 ms). This $30 \mathrm{~ms}$ effect of Semantic Gender Marking was significant, $F(1,17)=44.82, \mathrm{MSE}=352.05, P<0.01$. Moreover, RTs to words having feminine grammatical gender (654 ms) were shorter compared to masculine gender words (696 ms; F $(1,17)=35.01$, MSE $=352.01, P<0.01)$. Semantic Gender Marking and Gender of Target (i.e., masculine vs. feminine) were also found to interact with each other $(F(1,17)=48.30$, MSE $=360.51, P<0.01)$. Paired t-tests revealed that the difference between words of masculine versus feminine gender was not significant in the semantically genderunmarked condition (665 ms vs. $655 \mathrm{~ms}$, for masculine and feminine words, respectively; $t(17)=1.31, \mathrm{SD}=33.17$, n.s.), but this difference was significant in the gender-marked condition (726 ms vs. $653 \mathrm{~ms}$, for masculine and feminine words, respectively; $\mathrm{t}(17)=8.28, \mathrm{SD}=37.13, \mathrm{P}<0.01)$. The button-press latencies were not supported by the error analysis. The error rate in the semantically gender-marked condition (6.1\%) did not differ significantly from the semantically gender-unmarked condition (4.5\%), $\mathrm{t}(17)=1.82, \mathrm{SD}=0.03$, n.s.

\subsection{N200 analysis}

The N200 analysis is built on the assumption that the maximum of the increased negativity for no-go trials compared to go-trials mirrors the moment in time by which relevant information necessary to withhold a button-press response must have been encoded. The time necessary to encode the important information may, thus, be seen in the peak latency and amplitude of the N200.

ERP signals were averaged per participant and condition. Grand average ERPs were obtained separately for semantically gender-marked (see Fig. 1) and semantically gender-unmarked conditions (see Fig. 2). Fig. 3 shows grand average waveforms for each condition for 18 participants at midline sites (Fz, FCz, $\mathrm{Cz}$, and CPz). As can be seen, both conditions showed an N200 with no-go responses being more negative than go responses.

ERP difference waveforms (no-go minus go) were calculated per participant and condition. Fig. 4 displays the grand average difference waveforms for the marked and the 


\section{Gender-marked}
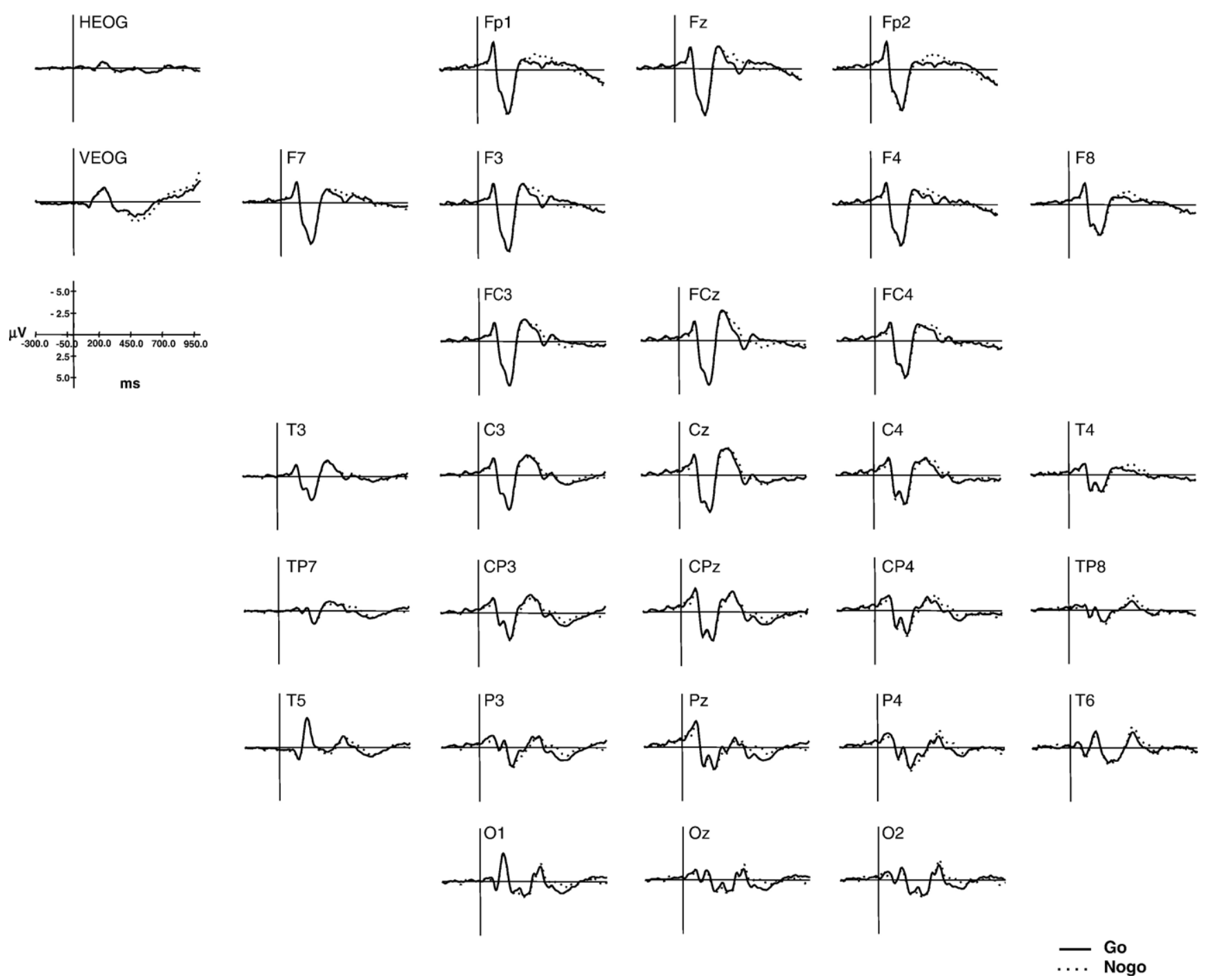

Fig. 1 - Grand average no-go and go ERPs for semantically marked trials. Displayed are 28 scalp electrodes plus two electrodes which monitored horizontal and vertical eye movements.

unmarked condition (left and middle panel, respectively). The figure shows (right panel) that the peak latency of the N200 effect corresponding to the semantically gender-marked condition precedes the gender-unmarked condition.

The statistical comparison of the ERP difference waveforms for the two conditions at four midline electrodes ( $\mathrm{Fz}, \mathrm{FCz}, \mathrm{Cz}$, and $\mathrm{CPz}$ ) supported the above description of the results based on visual inspection of the waveforms. For each participant, peak latency and peak amplitudes (voltage value at the peak) of the N200 effect between 350 and 600 ms were measured at each of the four electrode sites for correct trials. For the peak latencies, as well as peak amplitudes, repeated measures ANOVAs were carried out with Semantic Gender Marking, Gender of Target, and Electrode Site as factors.

Of interest was whether or not the latency and amplitude characteristics of the N200 effects differed between gendermarked and gender-unmarked targets. For the peak latencies, the main effect of Gender of Target (i.e., masculine vs. feminine) was not significant, $F(1,17)<1$. Furthermore, Gender of Target did not interact with any other factor. Therefore, we collapsed our data across Gender of Target for all subsequent analyses. The main effect of Semantic Gender Marking was significant, $F$ $(1,17)=9.60, \mathrm{MSE}=15385.05, \mathrm{P}<0.01$, indeed reflecting $\mathrm{a}$ difference in peak latencies. When the go/no-go decision was contingent on semantically gender-marked words, the mean peak latency of the $\mathrm{N} 200$ effect was $453 \mathrm{~ms}(\mathrm{SD}=77$ ). In contrast, when the go/no-go decision was contingent on semantically gender-unmarked words, the mean peak latency of the N200 was $517 \mathrm{~ms}(\mathrm{SD}=71)$. The mean latency difference of the two N200 effects was $64 \mathrm{~ms}$. Neither the main effect of Electrode Site nor the interaction between Electrode Site and Semantic Gender Marking was significant.

The peak amplitudes did not show a main effect of Gender of Target, $F(1,17)=1.76$, MSE $=0.43$, n.s., nor did this factor interact with any other factor. Therefore, for the remaining analyses we collapsed the data across Gender of Target. The 


\section{Gender-unmarked}
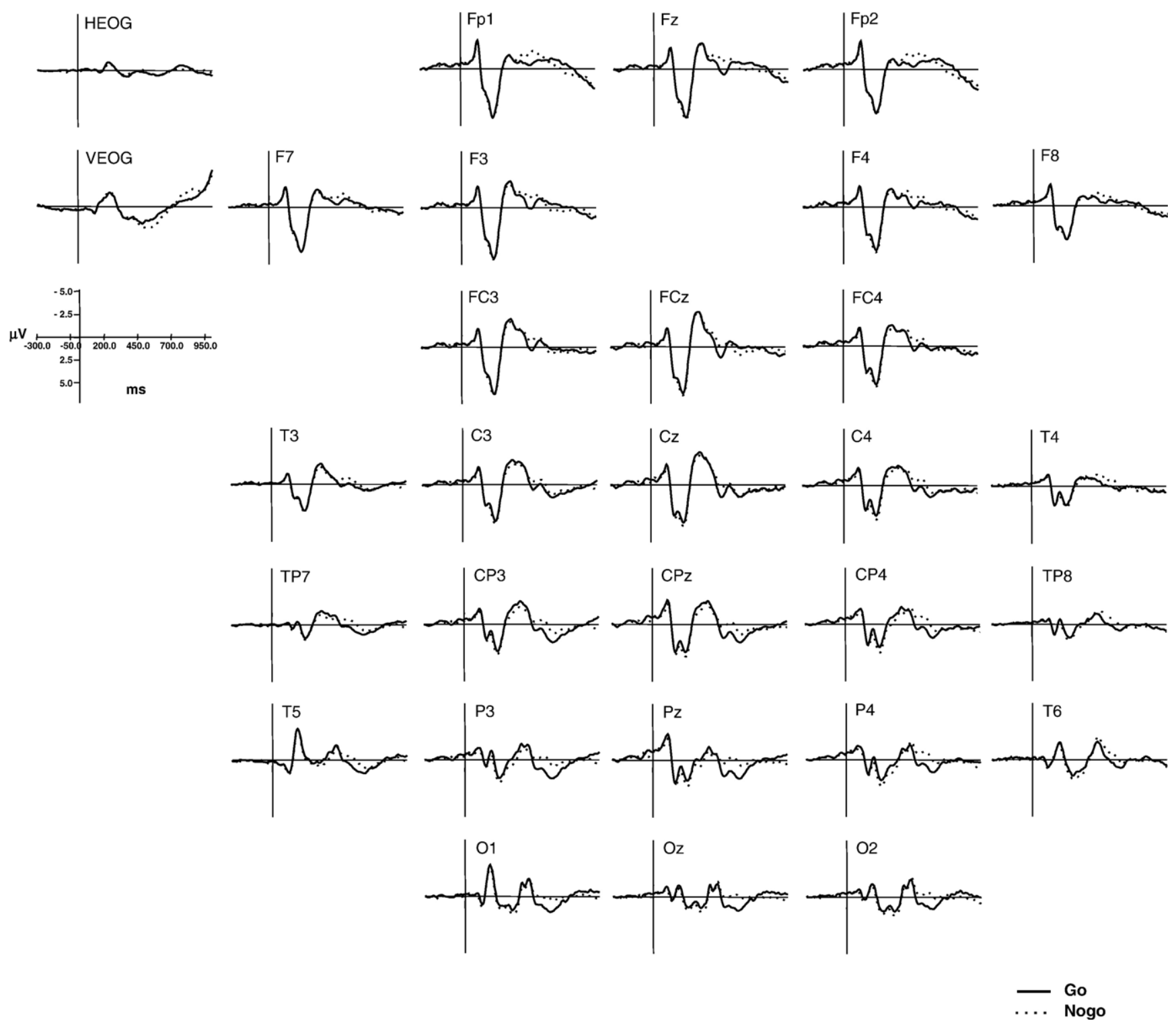

Fig. 2 - Grand average no-go and go ERPs for semantically unmarked trials. Displayed are 28 scalp electrodes plus two electrodes which monitored horizontal and vertical eye movements.

main effect of Semantic Gender Marking was not significant either, $F(1,17)=2.91, \mathrm{MSE}=2.03$, n.s. The mean peak amplitude of the $\mathrm{N} 200$ was $-2.01 \mu \mathrm{V}(\mathrm{SD}=0.83)$ in the semantically gendermarked condition and $-2.42 \mu \mathrm{V}(\mathrm{SD}=1.09)$ in the semantically gender-unmarked condition. The mean peak amplitude difference of the two N200 effects was $0.41 \mu \mathrm{V}$. The main effect of Electrode Site and the interaction between Electrode Site and Semantic Gender Marking were not significant.

\section{Discussion}

We investigated the influence of semantic category membership on syntactic decision-making by using a simple go/no-go paradigm combined with high-temporal resolution ERP. In this particular case, the N200 results speak to the temporal course of information flow related to response inhibition. Specifically, the N200 effect ("no-go minus go" ERPs) reflects an upper limit about the point in time at which information about whether an actual response needs to be made or withheld must have become available. This time is typically captured by the mean peak latency of the N200 (e.g., Rodriguez-Fornells et al., 2002; Schiller et al., 2003a,b; Schmitt et al., 2000, 2001a,b). Our N200 peak latencies (453 ms and $517 \mathrm{~ms}$, respectively) are well within the range of N200 effects reported in the language processing literature (RodriguezFornells et al., 2002; Schmitt et al., 2000, 2001a,b).

Here, we found that the N200 effect varied in latency as a function of the condition in which the go/no-go syntactic gender decision was made. More specifically, we found that 


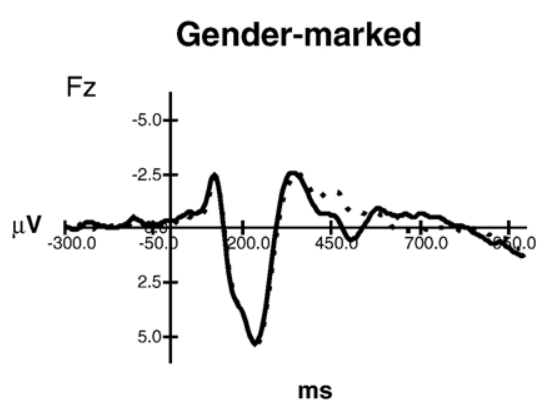

Gender-unmarked

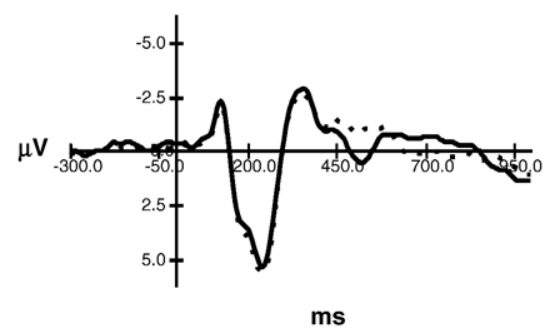

ms

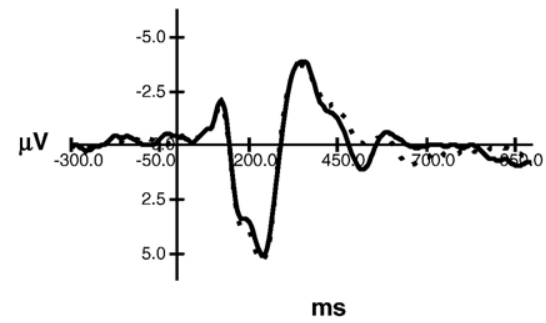

ms

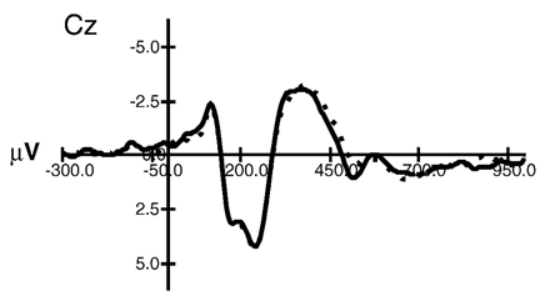

ms

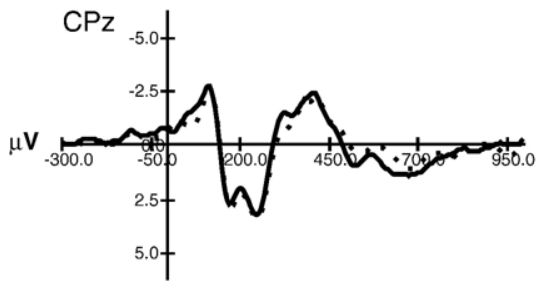

ms

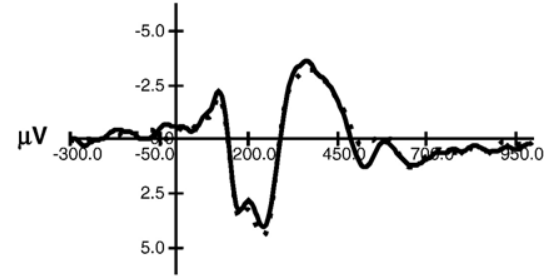

ms

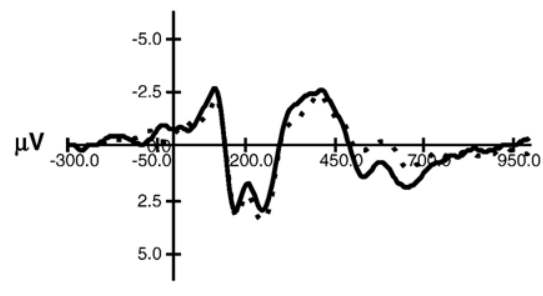

ms

. Go

Fig. 3 - Grand average no-go and go ERPs for semantically gender-marked and semantically gender-unmarked conditions. Semantically gender-marked conditions are shown in the left panel; semantically gender-unmarked conditions are shown in the right panel. Displayed are data from 18 participants over four midline electrode sites.

the N200 effect occurred $64 \mathrm{~ms}$ earlier when the go/no-go syntactic decision was made for semantically gender-marked words than when it was made for gender-unmarked words. This means that the information that blocked the response on no-go trials was available earlier in the semantically gendermarked condition than in the semantically gender-unmarked condition. The N200 peak latency results therefore suggest that semantic category membership information facilitated the decision about the syntactic (or grammatical) gender of a visually presented German noun.

These results provide additional information for the debate about the time course of information processing in language comprehension. If word comprehension occurs indeed in a cascaded manner (as suggested by McQueen et al., 2003), our results may indicate that semantic processing started prior to syntactic processing - leading to a syntactic decision - was finalized. In fact, the suggestion for cascaded processing is supported by similar results obtained by Schmitt et al. (2001a). These authors investigated the time courses of access to semantic and syntactic information during noun comprehension. The peak latencies of their N200 effect indicated that access to semantic information precedes access to syntactic information, and we show now that markedness of a syntactic feature, i.e., gender, at the semantic level facilitates subsequent syntactic access.

Moreover, in a very recent study by Müller and Hagoort (2006), native Dutch participants were requested to make decisions about the grammatical gender and the semantic category of visually presented words. In one task, the grammatical gender of the target word determined the 


\section{Difference Waves (nogo-go)}
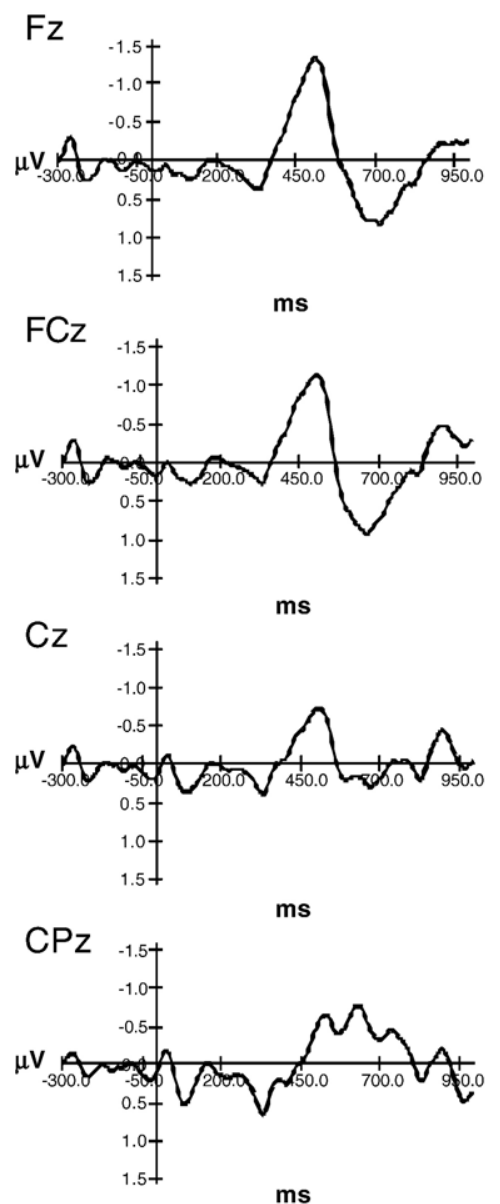

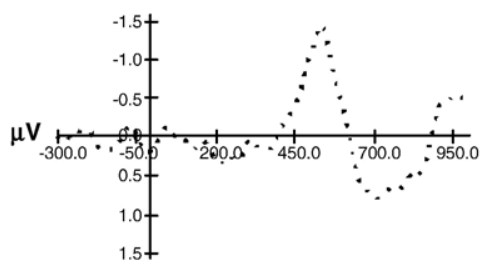

ms

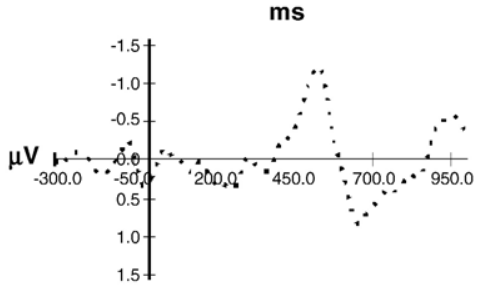

ms

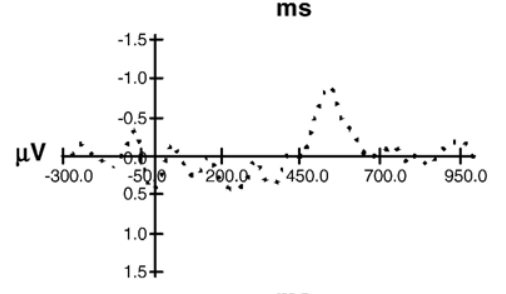

ms

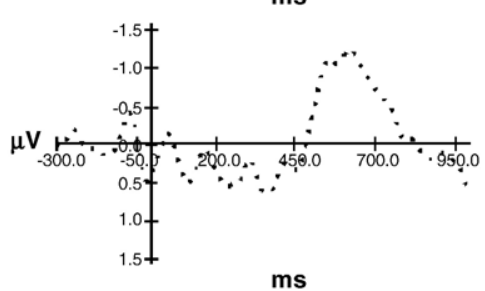

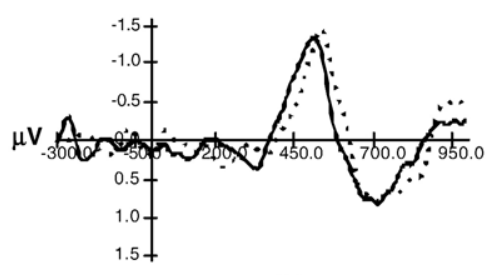

ms

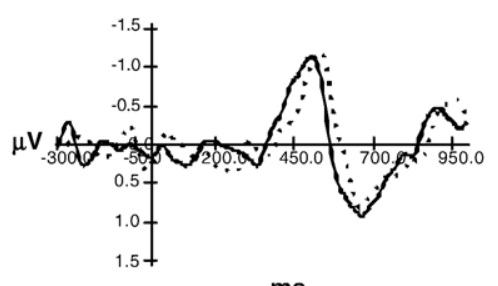

ms

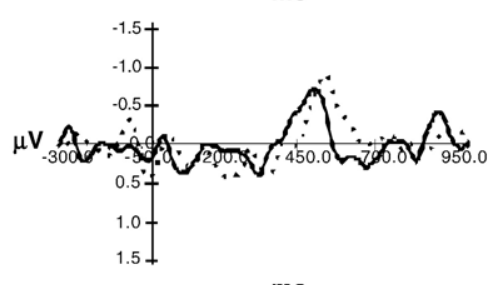

ms

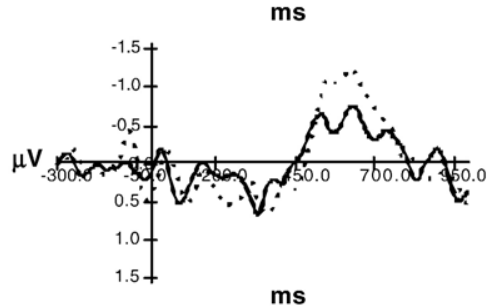

ms

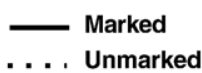

Fig. 4 - Grand average difference ERPs (no-go minus go) for semantically gender-marked and semantically gender-unmarked conditions. Semantically gender-marked conditions are shown in the left panel; semantically gender-unmarked conditions are shown in the middle panel. Both difference-waveforms are overlaid in the right panel. Displayed are data from 18 participants over four midline electrode sites.

response hand (left or right hand) and its semantic category determined response execution (go/no-go). In the other task, the dependencies were reversed, i.e., semantic category determined response hand and grammatical gender determined response execution. Lateralized readiness potentials (LRPs) indicated that response preparation took place on no-go-trials in the former, but not in the latter task. This indicated that semantic information was used for response preparation before gender information inhibited this process. Furthermore, an N200 effect occurred earlier when the decision whether or not to inhibit the response was based on semantic category information than when it was based on grammatical gender information. This study provided evidence that information about semantic categories of visually presented words was available earlier than their syntactic properties (e.g., grammatical gender), and our present results are in line with this interpretation.
The influence of semantic information on syntactic or grammatical processing is further supported by research investigating the role of biological gender (male vs. female) during syntactic processing (i.e., pronoun integration). For instance, Schmitt et al. (2002) showed that when a German noun referent was marked for biological gender (e.g., der Bub 'the boy'), this influenced pronoun processing. More specifically, the N400 component increased from congruent (e.g., er 'he') via neutral (e.g., es 'it') to incongruent (e.g., sie 'she') pronouns, demonstrating that semantic processing is involved in syntactic pronoun integration. In a similar study, Hammer et al. (2005) found the P600 to pronoun processing to vary as a function of biological gender marking in the noun antecedent. They interpreted this effect as a semantic influence on a syntactic integration process. In these two studies, just like in the current study, lexico-semantic features (i.e., biological gender) were shown to influence syntactic processes of word comprehension. 
How could this influence on syntactic processes work? We propose the involvement of a priming mechanism to account for the influence of the semantic information on syntactic decisions (see also Friederici and Jacobsen, 1999). Suppose that conceptual representations of words at the conceptualsemantic level have direct connections to gender nodes at the syntactic level. This assumption is motivated by the fact that historically grammatical gender used to be a full-fledged nominal category (like number) which was used to make distinctions in meaning. Take the reconstruction for IndoEuropean hímah ('winter', feminine), himás ('cold', masculine), and himam ('snow', neuter; Lehmann, 1958) as an example or compare the Old High German forms bluomo ('flower'; masculine) and bluoma ('blossom'; feminine; Leiss, 1999). In these examples, different gender-marking suffixes used to realize gender-specific meanings of a particular noun. When a semantically gender-marked word activates its meaning, via spreading of activation other category members also become activated (semantic priming; see Neely, 1991 for an overview). In the case of gender-associated semantic categories, more semantic-conceptual nodes are connected to a particular gender node at the syntactic level than in the case of gender-nonassociated semantic categories, and therefore the former can prime (i.e., pre-activate) a particular syntactic gender node more strongly than the latter.

Take, for instance, the gender-associated category fruit. When the target word Kiwi ('kiwi') is presented, it activates category members like Birne ('pear'), Pflaume ('plum'), Himbeere ('rasberry'), Feige ('fig'), Ananas ('pineapple'), etc. Most of the category members are feminine. When all activated category members spread activation to their gender nodes, the grammatical gender 'feminine' will receive a relatively high amount of activation because the category 'fruit' is gender-marked for feminine. Hence, at the time when the syntactic decision about the determiner of Kiwi is made (i.e., die) its corresponding gender (i.e., feminine) has already been pre-activated, thus facilitating the decision about the corresponding determiner. A target word such as Tisch ('table'), however, belonging to the gender-nonassociated semantic category furniture would not lead to the same extent of pre-activation of the corresponding grammatical gender because the category members of Tisch such as Stuhl ('chair', masculine), Bett ('bed', neuter), and Bank ('bench', feminine) are not predominantly connected to one grammatical gender. On this account, the semantic category members activated by the target word pre-activate their corresponding gender nodes at the lexical level and thus facilitate syntactic gender decisions (for example, in terms of reaching a specific activation threshold at the syntactic feature level earlier) compared to no semantic gender marking. We propose that faster gender decisions are reflected in earlier N200 peak latencies for gender-marked than for genderunmarked target words.

Alternatively, semantic-conceptual representations may not be connected directly with grammatical gender nodes, but via bidirectional connections between concepts and lexical nodes activation spreads back from the semantic-conceptual level to the lexical level (Levelt et al., 1999; see Introduction). Activation spreads automatically from lexical nodes to gender nodes, but these latter connections are presumably unidirectional (Van Berkum, 1996; Jescheniak, 1999). Since in a semantically gender-associated category such as fruit the majority of the semantic category members' lexical nodes is connected to one specific gender node (i.e., feminine in the case of fruit), pre-activating that gender node thus leading to faster gender decisions could be accounted for by the spreading back of activation from the semantic category level to lexical nodes. In the case of gender-unmarked target words, activation spreads back to fewer words of a particular gender, and therefore the priming effect of the gender node is weaker. ${ }^{1}$

However, when looking at our reaction time data, it does not seem to be the case that this priming effect leads to faster behavioral responses. The button-press latencies in the semantically gender-unmarked condition were $30 \mathrm{~ms}$ faster than in the semantically gender-marked condition. Nonetheless, this finding does not necessarily speak against the gender node priming. The N200, in our case, may be determined by the semantic category information pre-activating (priming) a syntactic node. The syntactic gender decision about the determiner form has to be made via the lexical representation, however. This decision process may be a function of the lexical activation of an item. For high-frequency items this process may be easier, for low-frequency items it may be more difficult and slower (Cattell, 1886; Monsell et al., 1989). When looking at the word frequency characteristics of the materials used in our study we noticed that in the semantically gendermarked condition, unlike the gender-unmarked condition, certain masculine semantic categories (i.e., stone and spice) unfortunately had extremely low frequencies of occurrence according to the CELEX database (Baayen et al., 1995; see Table 1). On average, the mean frequency per million was 19.3 for semantically gender-unmarked items but only 3.0 for semantically gender-marked items. Thus, lower frequency masculine words presumably slowed down the decision process due to slower activation of the corresponding lexical item, hence leading to slower button-presses. This is supported by the interaction found between Semantic Gender Marking and Gender of Target in the reaction time analysis.

The functional relevance of semantic priming at the syntactic/grammatical level for speech processing during comprehension may be the faster integration of words into the syntactic structure. Take, for instance, the German sentence Der Wert der Kiwi, der/die groß war, erstaunte jeden ('The value of the kiwi, which was big, impressed everybody'). The masculine relative pronoun der refers to Wert, whereas the feminine relative pronoun die refers to Kiwi. Both pronouns would be perfectly acceptable in the sentence. Knowing the gender of Kiwi (i.e., feminine) would help interpreting and integrating the relative pronoun and make parsing sentences like this easier. However, its gender could not be determined on the basis of the determiner alone since Kiwi appears in its genitive form (i.e., der Kiwi) and the form der predominantly functions as the musculine nominative singular determiner.

However, we cannot completely rule out a parallel processing architecture, in which semantic and syntactic information is activated simultaneously. In order for semantic information to speed up syntactic information availability in

\footnotetext{
${ }^{1}$ We would like to thank one of the reviewers for suggesting this alternative account.
} 


\begin{tabular}{lc}
$\begin{array}{l}\text { Table 1 - Overview of the mean frequency of occurrence } \\
\text { according to CELEX (Baayen et al., 1995) per semantic } \\
\text { category }\end{array}$ \\
$\begin{array}{l}\text { Semantic category } \\
\text { Mean frequency } \\
\text { (per 1 million words) of items } \\
\text { included per category }\end{array}$ \\
\hline Predator (masculine) & 6.2 \\
Spice (masculine) & 0.6 \\
Stone (masculine) & 2.0 \\
Fruit (feminine) & 1.9 \\
Musical instrument (feminine) & 5.3 \\
Insect (feminine) & 2.2 \\
Body part & 64.8 \\
Tool & 2.4 \\
Kitchen utensil & 6.9 \\
Furniture & 23.1 \\
Arms & 6.4 \\
Clothing & 12.1 \\
\hline
\end{tabular}

this alternative scenario, the duration of semantic processing would have to be shorter than the time needed for the syntactic decision. Conceptual-semantic nodes need to be connected to gender nodes in order to pre-activate them. Due to the lack of connections between conceptual-semantic and lexical nodes, this account does not work by simply assuming spreading back of information from the conceptual-semantic level to the lexical level.

In sum, we employed the N200 to monitor on-line language comprehension. More precisely, we investigated whether or not semantic gender information influenced syntactic gender decisions. The ERP data showed an earlier N200 effect for semantically gender-marked items than for semantically gender-unmarked items, suggesting an influence of semantic gender information on syntactic decision-making, such that semantically gender-marked words speed up syntactic gender processing by about $60 \mathrm{~ms}$.

\section{Experimental procedures}

\subsection{Participants}

Eighteen native speakers of German (11 female and 7 male, between 20 and 28 years of age; mean: 22.6 years) were paid to take part in the experiment after giving written informed consent. The ethical committee of the Faculty of Psychology of Maastricht University approved the study. All participants were undergraduate students, they were right-handed, reported to be neurologically healthy, and had normal or corrected-to-normal vision. Seven other participants were excluded from the analysis because of excessive (more than $40 \%$ of the trials) artifacts (e.g., eye blinks) and technical failures.

\subsection{Materials}

The stimuli were 192 simple white-on-black German monomorphemic nouns (96 feminine, 96 masculine; see Appendix A). Half of them were semantically (categorically) marked for a specific gender (e.g., der Tiger mas 'the tiger', belonging to the category of predators, a predominantly masculine category in German; die Kiwi fem 'the kiwi', belonging to the category of fruits, predominantly feminine) and half of them were semantically gender-unmarked (e.g.,

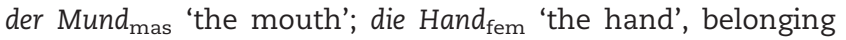
to the gender-non-associated category of body parts). The grammatical gender of German words can be marked biologically (i.e., natural gender, e.g., die Mutter 'the $\mathrm{fem}_{\mathrm{f}}$ mother') and/or phonologically (that is, phonological gender assignment rules identified by linguistic research (for details see Köpcke and Zubin, 1983, 1984); i.e., a word can have a "feminine" or a "masculine" phonology, e.g., words beginning with the segments $/ \mathrm{kn} /$ are generally masculine in German: der Knochen 'the mas bone'). The phonological gender marking in the feminine and masculine categories did not differ between the semantically gender-marked and genderunmarked conditions. Each character of the words covered approximately $0.3^{\circ}$ of visual angle. All targets were between 3 and 10 letters long (mean between 6.0 and 6.3 letters per target category, masculine and feminine, respectively) subtending between $0.9^{\circ}$ and $3.0^{\circ}$ of visual angle. The target words had a mean frequency of occurrence of 17.5 per million ( $\mathrm{SD}=41.6$; range: $0-46)$ and 18.8 per million $(\mathrm{SD}=51.7$; range: $0-65 ;$ masculine gender-marked and feminine gender-marked, respectively) as determined by the CELEX data base (Baayen et al., 1995). An overview of all semantic categories and the corresponding mean frequencies of occurrence for the items included in each category can be found in Table 1.

\subsection{Design}

Participants were tested on two types of experimental blocks (go masculine/no-go feminine and go feminine/no-go masculine) with the same semantically gender-marked and semantically gender-unmarked words. Participants received a block containing 20 practice trials before each experimental block of 192 trials. The sequence of words was randomized in each block and for each participant. There was one feminine go and one masculine go block, each of which was repeated once to increase the power.

\subsection{Procedure}

Participants were tested individually while seated in a soundproof, electrically shielded, chamber in front of a computer screen. In each block, the participants were required to make a syntactic decision, by means of a right hand buttonpress. The syntactic decision consisted of deciding whether the visually presented word took the masculine determiner (der) or the feminine determiner (die). For half of the blocks, participants were asked to press the response button when the determiner of the presented word was der and withhold when it was die. For the other half, participants were asked to press the response button when the determiner of the presented word was die and withhold when it was der. This way, a go and no-go response could be obtained for each target word. Each experimental block lasted approximately $10 \mathrm{~min}$, and the entire experiment lasted about $2 \mathrm{~h}$, including the placement of the electrode cap. 
A trial began with the presentation of a fixation cross in the middle of the computer screen. The fixation cross was followed by a word after a variable delay of between 1,800 $\mathrm{ms}$ and 2,300 ms. The period between fixation and stimuli presentation was varied in order to avoid that participants would build up a systematic expectancy in the form of a contingent negative variation (Walter et al., 1964). The words were presented on the screen for $300 \mathrm{~ms}$. As soon as possible after the word appeared on the screen, participants were required to give their response by pressing the response button. Reaction times were registered automatically. The following trial began after an interval of 1,000 ms. Participants were instructed to rest their arms on the elbow rest of the armchair and to put their index finger on the right button of the button-box in front of them. They were instructed not to speak, blink, or move their eyes while a word was on the screen.

\subsection{Apparatus and recordings}

Button-press responses were measured from word onset with a time-out limit (the moment in time after which responses were registered as missing) of $1500 \mathrm{~ms}$. Time-outs and errors (wrong responses) were excluded from further analyses. The electroencephalogram (EEG) was recorded from 29 scalp sites (extended version of the 10/20 system) using tin electrodes mounted in an electrode cap with reference electrodes placed at the mastoids. Signals were collected using the left mastoid electrode as a reference and rereferenced off-line to the mean of the activity at the two mastoid electrodes. The EEG signal was digitized at $250 \mathrm{~Hz}$. To monitor vertical eye movements and blinks, electrodes were placed above the eyebrow and under the lower orbital ridge in a bipolar montage. Bipolar electrodes placed on the right and left external canthus registered horizontal eye movement. Eye movements were recorded for later off-line rejection of contaminated trials. Electrode impedance was kept below $5 \mathrm{k} \Omega$ for the EEG and eye movement recordings. Signals were amplified with a band-pass filter from 1 to $30 \mathrm{~Hz}$ and off-line band-pass filtered from 1 to $8 \mathrm{~Hz}$ for graphical display. Epochs of $1,300 \mathrm{~ms}$ [ $-300 \mathrm{~ms}$ to $+1000 \mathrm{~ms}$ ] were obtained, including a $300-\mathrm{ms}$ pre-stimulus baseline. The original number of trials per condition per individual was $48 \times 2=96$.

Trials of correct responses were visually inspected. Trials contaminated by eye movements or technical failure within the critical time window were rejected from averaging by a computer program using individualized rejection criteria. On average, $12.5 \%$ of the trials were excluded from further analysis (including ERP artifacts and incorrect responses). To isolate the $\mathrm{N} 200$, difference waves were computed by subtracting the ERP of the go trials from those of the no-go trials. In the difference waveforms, the latency and amplitude of the most negative peak in the 350-600 ms time window was established. Visual inspection of the waveforms showed that the second negative peak fell within this time window. Moreover, peaks were verified visually. As the N200 is generally largest for midline fronto-central electrodes (Thorpe et al., 1996), the analyses were restricted to the electrodes $\mathrm{Fz}$, $\mathrm{FCz}, \mathrm{Cz}$, and $\mathrm{CPz}$.

\section{Acknowledgments}

The work presented in this manuscript is supported by NWO grant no. 453-02-006 to Niels O. Schiller. The manuscript benefited from discussions at the Tenth Annual Meeting of the Cognitive Neuroscience Society in New York, April 2003. Bernadette M. Jansma used to publish under her maiden name Schmitt. The authors would like to thank two anonymous reviewers for their valuable comments.

\section{Appendix A. \\ Target words and corresponding semantic categories used in the experiment}

\begin{tabular}{|c|c|c|c|}
\hline $\begin{array}{l}\text { Semantically } \\
\text { gender-marked } \\
\text { (masculine) }\end{array}$ & $\begin{array}{l}\text { Semantic } \\
\text { category }\end{array}$ & $\begin{array}{c}\text { Semantically } \\
\text { gender-marked } \\
\text { (feminine) }\end{array}$ & $\begin{array}{l}\text { Semantic } \\
\text { category }\end{array}$ \\
\hline Tiger ('tiger') & 1 & Aprikose ('apricot') & 4 \\
\hline Panter ('panther') & 1 & Banane ('banana') & 4 \\
\hline Luchs ('lynx') & 1 & Feige ('fig') & 4 \\
\hline Wolf ('wolf') & 1 & Limone ('lime’) & 4 \\
\hline Fuchs ('fox') & 1 & Zitrone ('lemon') & 4 \\
\hline Habicht ('hawk') & 1 & Melone ('melon') & 4 \\
\hline Hai ('shark') & 1 & Nektarine ('nectarine') & 4 \\
\hline Bussard ('buzzard') & 1 & Mandarine ('tangerine') & 4 \\
\hline Adler ('eagle') & 1 & Orange ('orange') & 4 \\
\hline Hermelin ('ermine') & 1 & Birne ('pear') & 4 \\
\hline Marder ('marten') & 1 & Pflaume ('plum') & 4 \\
\hline Löwe ('lion’) & 1 & Kirsche ('cherry') & 4 \\
\hline Gepard ('cheetah') & 1 & Dattel ('date') & 4 \\
\hline Puma ('puma') & 1 & Kiwi ('kiwi’) & 4 \\
\hline Falke ('falcon') & 1 & Ananas ('pineapple') & 4 \\
\hline Koyote ('coyote') & 1 & Traube ('grape') & 4 \\
\hline Zimt ('cinnamon') & 2 & Balalaika ('balalaika') & 5 \\
\hline Dill ('dill’) & 2 & Oboe ('oboe') & 5 \\
\hline Lauch ('leek') & 2 & Klarinette ('clarinette') & 5 \\
\hline Eukalyptus ('eucalyptus') & 2 & Flöte ('flute') & 5 \\
\hline Ingwer ('ginger') & 2 & Harfe ('harp') & 5 \\
\hline Lavendel ('lavender') & 2 & Zither ('zither') & 5 \\
\hline Oregano ('oregano') & 2 & Posaune ('trombone') & 5 \\
\hline Saffran ('saffran') & 2 & Trompete ('trumpet') & 5 \\
\hline Salbei ('sage') & 2 & Tuba ('tuba') & 5 \\
\hline Thymian ('thyme') & 2 & Geige ('violin') & 5 \\
\hline Baldrian ('valerian') & 2 & Bratsche ('viola') & 5 \\
\hline Lorbeer ('bay leaf') & 2 & Trommel ('drum') & 5 \\
\hline Kerbel ('chervil') & 2 & Triangel ('triangle') & 5 \\
\hline Koniander ('coriander') & 2 & Orgel ('organ') & 5 \\
\hline Kümmel ('caraway’) & 2 & Gitarre ('guitar') & 5 \\
\hline Pfeffer ('pepper') & 2 & Ukulele ('ukulele') & 5 \\
\hline Marmor ('marble') & 3 & Ameise ('ant') & 6 \\
\hline Granit ('granite') & 3 & Zecke ('tick') & 6 \\
\hline Fels ('rock') & 3 & Fliege ('fly’) & 6 \\
\hline Schiefer ('slate') & 3 & Wespe ('wasp') & 6 \\
\hline Quarz ('quartz') & 3 & Biene ('bee') & 6 \\
\hline Rubin ('ruby') & 3 & Motte ('moth') & 6 \\
\hline Saphir ('sapphire') & 3 & Hornisse ('hornet') & 6 \\
\hline Diamant ('diamond') & 3 & Mücke ('midge') & 6 \\
\hline Opal ('opal') & 3 & Termite ('termite') & 6 \\
\hline Topas ('topaz') & 3 & Schabe ('cockroach') & 6 \\
\hline
\end{tabular}




\section{Appendix A (continued)}

\begin{tabular}{|c|c|c|c|}
\hline $\begin{array}{l}\text { Semantically } \\
\text { gender-marked } \\
\text { (masculine) }\end{array}$ & $\begin{array}{l}\text { Semantic } \\
\text { category }\end{array}$ & $\begin{array}{c}\text { Semantically } \\
\text { gender-marked } \\
\text { (feminine) }\end{array}$ & $\begin{array}{l}\text { Semantic } \\
\text { category }\end{array}$ \\
\hline Malachit ('malachite') & 3 & Grille ('cricket') & 6 \\
\hline Bauxit ('bauxite') & 3 & Milbe ('mite') & 6 \\
\hline Basalt ('basalt') & 3 & Libelle ('dragonfly') & 6 \\
\hline Smaragd ('emerald') & 3 & Hummel ('bumblebee') & 6 \\
\hline Onyx ('onyx') & 3 & Laus ('louse') & 6 \\
\hline Graphit ('graphite') & 3 & Tarantel ('tarantula') & 6 \\
\hline Arm ('arm') & 7 & Lippe ('lip') & 7 \\
\hline Fuß ('foot') & 7 & Hand ('hand') & 7 \\
\hline Finger ('finger') & 7 & Stirn ('forehead') & 7 \\
\hline Mund ('mouth') & 7 & Schulter ('shoulder') & 7 \\
\hline Hals ('neck') & 7 & Nase ('nose') & 7 \\
\hline Rücken ('back') & 7 & Brust ('chest') & 7 \\
\hline Bauch ('belly') & 7 & Hüfte ('hip') & 7 \\
\hline Nacken ('nape') & 7 & Backe ('cheek') & 7 \\
\hline Hammer ('hammer') & 8 & Säge ('saw') & 8 \\
\hline Spaten ('spade') & 8 & Feile ('file') & 8 \\
\hline Bohrer ('drill') & 8 & Zange ('tongs') & 8 \\
\hline Spachtel ('scraper') & 8 & Schaufel ('blade') & 8 \\
\hline Hobel ('plane') & 8 & Harke ('rake') & 8 \\
\hline Amboß ('ambos') & 8 & Fräse ('milling cutter') & 8 \\
\hline Meißel ('bit') & 8 & Axt ('ax') & 8 \\
\hline Besen ('broom') & 8 & Sichel ('sickle') & 8 \\
\hline Topf ('pot') & 9 & Pfanne ('pan') & 9 \\
\hline Teller ('plate') & 9 & Gabel ('fork') & 9 \\
\hline Mixer ('blender') & 9 & Tasse ('cup') & 9 \\
\hline Trichter ('funnel') & 9 & Raspel ('rasp') & 9 \\
\hline Löffel ('spoon') & 9 & Schere ('scissors') & 9 \\
\hline Kessel ('boiler') & 9 & Reibe ('grater') & 9 \\
\hline Quirl ('beater') & 9 & Waage ('scale') & 9 \\
\hline Becher ('beaker') & 9 & Flasche ('bottle') & 9 \\
\hline Stuhl ('chair') & 10 & Couch ('couch') & 10 \\
\hline Tisch ('table') & 10 & Bank ('bench') & 10 \\
\hline Hocker ('stool') & 10 & Liege ('lounger') & 10 \\
\hline Schrank ('closet') & 10 & Lampe ('lamp') & 10 \\
\hline Sessel ('armchair’) & 10 & Gardine ('curtain') & 10 \\
\hline Teppich ('carpet') & 10 & Matraze ('mattress') & 10 \\
\hline Spiegel ('mirror') & 10 & Gardrobe ('wardrobe') & 10 \\
\hline Diwan ('divan') & 10 & Kiste ('box') & 10 \\
\hline Speer ('spear') & 11 & Granate ('grenade') & 11 \\
\hline Säbel ('sabre') & 11 & Bombe ('bomb') & 11 \\
\hline Dolch ('dagger’) & 11 & Pistole ('gun') & 11 \\
\hline Pfeil ('arrow') & 11 & Kanone ('cannon') & 11 \\
\hline Colt ('colt') & 11 & Harpune ('harpoon') & 11 \\
\hline Knüppel ('club') & 11 & Muskete ('musket') & 11 \\
\hline Degen ('epee') & 11 & Lanze ('lance') & 11 \\
\hline Revolver ('revolver') & 11 & Patrone ('round') & 11 \\
\hline Schuh ('shoe') & 12 & Bluse ('blouse') & 12 \\
\hline Strumpf ('stocking') & 12 & Hose ('pants') & 12 \\
\hline Rock ('skirt') & 12 & Socke ('sock') & 12 \\
\hline Mantel ('coat') & 12 & Jacke ('jacket') & 12 \\
\hline Schal ('scarf') & 12 & Weste ('vest') & 12 \\
\hline Stiefel ('boot') & 12 & Mütze ('cap') & 12 \\
\hline Gürtel ('belt') & 12 & Krawatte ('tie') & 12 \\
\hline Hut ('hat') & 12 & Sandale ('sandal') & 12 \\
\hline
\end{tabular}

Note. Semantic categories are indicated by digits (i.e., 1 = Raubtier ('predator'); 2 = Gewürz ('spice'); 3 = Gestein ('stone'); 4 = Obst ('fruit'); 5 = Musikinstrument ('musical instrument'); 6 = Insekt ('insect'); 7 = Körperteil ('bodypart'); 8 = Werkzeug ('tool'); 9 = Küchenutensiel ('kitchen utensil'); 10 = Möbel ('furniture'); 11 = Waffen ('weapons'); $12=$ Kleidung ('clothes')).

\section{R E F E R E N C E S}

Baayen, R.H., Piepenbrock, R., Gulikers, L., 1995. The CELEX lexical database. Linguistic Data Consortium. University of Pennsylvania, Philadelphia (CD-ROM).

Caramazza, A., 1997. How many levels of processing are there in lexical access? Cogn. Neuropsychol. 14, 177-208.

Cattell, J.M., 1886. The time taken up by cerebral operations. Mind 11, 220-242, 77-392, 524-538.

Coltheart, M., Rastle, K., Perry, C., Langdon, R., Ziegler, J., 2001. DRC: a dual route cascaded model of visual word recognition and reading aloud. Psychol. Rev. 108, 204-256.

Corbett, G., 1991. Gender. Cambridge Univ. Press, Cambridge.

Cutler, A., Clifton, C., 1999. Comprehending spoken language: a blueprint of the listener. In: Brown, C.M., Hagoort, P. (Eds.), The Neurocognition of Language. Oxford Univ. Press, New York, pp. 123-166.

Dell, G.S., 1986. A spreading-activation theory of retrieval in sentence production. Psychol. Rev. 93, 283-321.

Friederici, A.D., Jacobsen, T., 1999. Processing grammatical gender during language comprehension. J. Psycholinguist. Res. 28, 467-484.

Gemba, H., Sasaki, K., 1989. Potential related to no-go reaction of go/no-go hand movement task with color discrimination in human. Neurosci. Lett. 101, 263-268.

Hammer, A., Jansma, B.M., Lamers, M., Münte, T.F., 2005. Pronominal reference in sentences about persons or things: An electrophysiological approach. J. Cogn. Neurosci. 17, 227-239.

Jescheniak, J.D., 1999. Gender priming in picture naming: modality and baseline effects. J. Psycholinguist. Res. 28, 729-737.

Jodo, E., Kayama, Y., 1992. Relation of a negative ERP component to response inhibition in a go/no-go task. Electroencephalogr. Clin. Neurophysiol. 82, 477-482.

Köpcke, K.-M., Zubin, D., 1983. Die kognitive Organisation der Genuszuweisung zu den einsilbigen Nomen der deutschen Gegenwartssprache (The cognitive organization of gender assignment in monosyllabic nouns of contemporary German). Z. Ger. Linguist. 11, 166-182.

Köpcke, K.-M., Zubin, D., 1984. Sechs Prinzipien für die Genuszuweisung im Deutschen: Ein Beitrag zur natürlichen Klassifikation (Six principles of gender assignment in German: A contribution to natural classification). Linguist. Ber. 93, 26-50.

Kutas, M., Schmitt, B.M., 2003. Language in microvolts. In: Banich, M.T., Mack, M.A. (Eds.), Mind, Brain, and Language: Multidisciplinary Perspectives. Lawrence Erlbaum Associates Incorporated, New York, pp. 171-209.

Lehmann, W.P., 1958. On earlier stages of the Indo-European nominal inflection. Language 34, 179-202.

Leiss, E., 1999. Gender in Old High German. In: Unterbeck, B., Rissanen, M. (Eds.), Gender in Grammar and Cognition. Mouton de Gruyter, Berlin, pp. 225-244.

Levelt, W.J.M., Roelofs, A., Meyer, A.S., 1999. A theory of lexical access in speech production. Behav. Brain Sci. 22, 1-75.

Marx, E., 1999. Gender processing in speech production: evidence from German speech errors. J. Psycholinguist. Res. 28, 601-621.

McQueen, J.M., Dahan, D., Cutler, A., 2003. Continuity and gradedness in speech processing. In: Schiller, N.O., Meyer, A.S (Eds.), Phonetics and Phonology in Language Comprehension and Production: Differences and Similarities. Mouton de Gruyter, Berlin, pp. 39-78.

Monsell, S., Doyle, M.C., Haggard, P.N., 1989. Effects of frequency on visual word recognition tasks: where are they? J. Exp. Psychol. Gen. 118, 43-71.

Müller, O., Hagoort, P., 2006. Access to lexical information in language comprehension: semantics before syntax. J. Cogn. Neurosci. 18, 84-96.

Neely, J.H., 1991. Semantic priming effects in visual word 
recognition: a selective review of current findings and theories. In: Besner, D., Humphreys, G.W. (Eds.), Basic Processes in Reading. Lawrence Erlbaum Associates, Hillsdale, NJ, pp. 264-336.

Norris, D., McQueen, J.M., Cutler, A., 2000. Merging information in speech recognition: feedback is never necessary. Behav. Brain Sci. 23, 299-325.

Pfefferbaum, A., Ford, J.M., Weller, B.J., Kopell, B.S., 1985. ERPs to response production and inhibition. Electroencephalogr. Clin. Neurophysiol. 60, 423-434.

Radeau, M., Van Berkum, J.J.A., 1996. Gender decision. Lang. Cogn. Proc. 11, 605-610.

Rodriguez-Fornells, A., Schmitt, B.M., Kutas, M., Münte, T.F., 2002. Electrophysiological estimates of the time course of semantic and phonological encoding during listening and naming. Neuropsychologia 40, 778-787.

Schiller, N.O., Caramazza, A., 2003. Grammatical feature selection in noun phrase production: evidence from German and Dutch. J. Mem. Lang. 48, 169-194.

Schiller, N.O., Bles, M., Jansma, B.M., 2003a. Tracking the time course of phonological encoding in speech production: an event-related brain potential study. Cogn. Brain Res. 17, 819-831.

Schiller, N.O., Münte, T.F., Horemans, I., Jansma, B.M., 2003b. The influence of semantic and phonological factors on syntactic decisions: an event-related brain potential study. Psychophysiology 40, 869-877.

Schmitt, B.M., Münte, T.F., Kutas, M., 2000. Electrophysiological estimates of the time course of semantic and phonological encoding during implicit picture naming. Psychophysiology 37, 473-484.

Schmitt, B.M., Rodriguez-Fornells, A., Kutas, M., Münte, T.F., 2001a. Electrophysiological estimates of semantic and syntactic information access during tacit picture naming and listening to words. Neurosci. Res. 41, 293-298.

Schmitt, B.M., Schiltz, K., Zaake, W., Kutas, M., Münte, T.F., 2001b.
An electrophysiological analysis of the time course of conceptual and syntactic encoding during tacit picture naming. J. Cogn. Neurosci. 13, 510-522.

Schmitt, B.M., Lamers, M., Münte, T.F., 2002. Electrophysiological estimates of biological and syntactic gender violation during pronoun processing. Cogn. Brain Res. 14, 333-346.

Schwichtenberg, B., Schiller, N.O., 2004. Semantic gender assignment regularities in German. Brain Lang. 90, 326-337.

Seidenberg, M.S., 1995. Visual word recognition-An overview. In: Miller, J.L., Eimas, P.D. (Eds.), Speech, Language, and Communication. Academic Press, San Diego, pp. 138-180.

Tanenhaus, M.K., Trueswell, J.C., 1995. Sentence comprehension. In: Miller, J.L., Eimas, P.D. (Eds.), Speech, Language, and Communication. Academic Press, San Diego, pp. 217-262.

Thorpe, S., Fize, D., Marlot, C., 1996. Speed of processing in the human visual system. Nature 381, 520-522.

Van Berkum, J.J.A., 1996. The psycholinguistics of grammatical gender. Unpublished PhD dissertation. Nijmegen University Press, Nijmegen.

Van Turennout, M., Hagoort, P., Brown, C.M., 1997. Electrophysiological evidence on the time course of semantic and phonological processes in speech production. J. Exp. Psychol. Learn. 23, 787-806.

Van Turennout, M., Hagoort, P., Brown, C.M., 1998. Brain activity during speaking: from syntax to phonology in 40 milliseconds. Science 280, 572-574.

Walter, W.G., Cooper, R., Aldridge, V.J., McCallum, W.C., Winter, A.L., 1964. Contingent negative variation: an electric sign of sensory motor association and expectancy in the human brain. Nature 203, 380-384.

Zubin, D., Köpcke, K.-M., 1986. Gender and folk taxonomy: the indexical relation between grammatical and lexical categorization. In: Craig, C. (Ed.), Noun Classes and Categorization. Proceedings of a symposium on categorization and noun classification, Eugene, Oregon, October 1983. John Benjamins, Amsterdam, pp. 139-180. 